\title{
ANALISIS EFISIENSI BANK UMUM KONVENSIONAL DI INDONESIA MENGGUNAKAN METODE DATA EVELOPMENT ANALYSIS (DEA) PADA TAHUN 2014-2018
}

\author{
Naili Farchah *) \\ Ida Savitri Kusmargiani **) \\ *)nailif96@gmail.com
}

\begin{abstract}
The purpose of the research is to analayze efficiency level of Commercial Bank in Indonesia (Bank Mandiri, Bank BNI, Bank BRI, Bank BTN, Bank BCA, Bank Danamon, Bank CIMB and Bank PAN) 2014-2018 period with Data Envelopment Analysis (DEA) method. Data used in this research is secondary data taken from Financial Statement Publication issued by Otoritas Jasa Keuangan (OJK) 2014-2018 period.Bank used in this reseach is eight bank which include in BUKU 4. Length of research period is five years from 2014 until 2018. This research uses input and output variable with Data Envelopment Analysis (DEA) method.

The result of research in 2014 all bank object efficient. In 2015 and 2016 inefficiency bank is BNI. In 2017 and 2018 inefficiency banks is Mandiri and BNI. Based on invention can be concluded that national foreign exchange private bank (BUSN) more efficiency than government bank in period research
\end{abstract}

Keywords : Efficiency, DEA Method, BUMN Bank, BUSN Devisa

*) Mahasiswa Tugas Akhir Prodi Keuangan dan Perbankan Jurusan Akuntansi Politeknik Negeri Semarang

**) Dosen Jurusan Akuntansi Politeknik Negeri Semarang

\section{PENDAHULUAN}

\section{Latar Belakang}

Perbankan adalah segala sesuatu yang berkaitan dengan bank, mencakup kelembagaan, kegiatan usaha, cara, dan proses dalam melaksanakan kegiatan usaha. Perbankan Indonesia berasaskan demokrasi ekonomi dimana kegiatannya dilakukan oleh rakyat, dari rakyat, dan untuk rakyat dengan tujuan untuk menyejahterakan rakyat dengan menggunakan prinsip kehati-hatian.

Bank adalah badan usaha yang kegiatannya sebagai lembaga intermediasi, yaitu penghimpun dana dari masyarakat dalam bentuk simpanan dan menyalurkan kembali dalam bentuk kredit atau bentuk- bentuk lainnya yang berhubungan dengan pemenuhan kebutuhan dan keinginan masyarakat.

Berdasarkan Undang-Undang Negara Republik Indonesia Nomor 10 Tahun 1998 Tanggal 10 November 1998 tentang perbankan yang dimaksud dengan bank adalah badan usaha yang menghimpun dana dari masyarakat dalam bentuk simpanan dan menyalurkannya kepada masyarakat dalam bentuk kredit dan atau bentuk-bentuk lainnya dalam rangka meningkatkan taraf hidup rakyat banyak. 
Statistik Perbankan Indonesia Otoritas Jasa Keuangan (OJK) menunjukkan bahwa jumlah bank pada September 2017 sebanyak 115 bank. Artinya telah berkurang 5 dari posisi 2013 yang masih berjumlah 120 bank. Jumlah bank terbanyak adalah kelompok Bank Umum Swasta Nasional (BUSN) Devisa yaitu 42 bank. Jumlah ini berambah 6 bank dibanding pada tahun 2013 sebanyak 36 bank. Kemudian Bank Pembangunan Daerah (BPD) sebanyak 27 bank, dan kelompok BUSN Non Devisa sebanyak 21 bank, jumlah ini berkurang 9 bank dari sebelumnya mencapai 30 bank. Lalu kelompok bank campuran sebanyak 12 bank, bank asing berjumlah 9 bank, serta Bank Persero sebanyak 4 bank.

Selain menurunnya jumlah bank saat ini hal lain yang menjadi permasalahan yaitu adanya 48 bank yang labanya anjlok pada 2017 dan 12 bank tercatat merugi. Pada tahun 2018 pertumbuhan kredit masih terhalang, baik dari sisi demand maupun supply. (Infobank, Juli 2018).

Menanggapi hal ini perbankan yang mampu bertahan di industri perbankan dan tidak mengalami penurunan bahkan mengalami kenaikan jumlah adalah Bank Umum Swasta Nasional Devisa dan Bank Pemerintah. Untuk itu bank-bank tersebut layak untuk diketahui kinerjanya agar dapat dijadikan tuntunan bagi bank lainnya dalam peningkatan kinerja. Salah satu cara untuk mengetahui kinerja perbankan adalah dengan penilaian efisiensi.

Efisiensi menilai kemampuan menghasilkan output secara maksimal dengan input yang ada. Tingkat efisiensi yang dicapai merupakan cerminan dari kualitas kinerja yang baik. Pengukuran efisiensi perbankan biasanya dilakukan dengan analisis rasio BOPO, namun dalam penelitian ini menyajikan pendekatan alternatif dalam analisis efisiensi menggunakan metode DEA.

Berdasarkan latar belakang diatas permasalahan dalam penelitian ini adalah penurunan laba, bank rugi dan penurunan jumlah bank. Tujuan penelitian ini adalah Untuk mengetahui kinerja Bank Umum Swasta Nasional dan Bank Pemerintah dalam menghasilkan nilai efisiensi pada tahun 2014-2018 berdasarkan metode Data Envelopment Analysis (DEA), menganalisis perbedaan dari kinerja Bank Umum Swasta Nasional dan Bank Pemerintah dalam menghasilkan nilai efisiensi pada tahun 2014-2018 berdasarkan metode Data Envelopment Analysis (DEA), menyusun strategi untuk mengembangkan kebijakan-kebijakan atas kinerja tingkat efisiensi Bank Umum Swasta Nasional Devisa dan Bank Pemerintah pada tahun 20142018 berdasarkan metode Data Envelopment Analysis (DEA).

\section{KAJIAN PUSTAKA}

\section{Bank}


Bank adalah badan usaha yang menghimpun dana dari masyarakat dalam bentuk simpanan dan menyalurkannya kepada masyarakat dalam bentuk kredit dan atau bentuk-bentuk lainnya dalam rangka meningkatkan taraf hidup rakyat banyak (Undang-undang Republik Indonesia Nomor 10 Tahun 1998 Tentang Perbankan). Sedangkan menurut Kasmir (2012:12) Bank adalah lembaga keuangan yang kegiatan utamanya adalah menghimpun dana dari masyarakat dan menyalurkannya kembali dana tersebut ke masyarakat serta memberikan jasa bank lainnya.

\section{Asas, Fungsi dan Tujuan Bank}

Dalam pasal 2, 3 dan 4 Undang-undang Nomor 10 tahun 1998 Tentang Perbankan, Perbankan Indonesia dalam melakukan usahanya berasaskan demokrasi ekonomi dengan menggunakan prinsip kehati-hatian. Fungsi utama perbankan Indonesia adalah sebagai penghimpun dan penyalur dana masyarakat. Perbankan Indonesia bertujuan menunjang pelaksanaan pembangunan nasional dalam rangka meningkatkan pemerataan, pertumbuhan ekonomi, dan stabilitas nasional ke arah peningkatan kesejahteraan rakyat banyak.

\section{Jenis-Jenis Bank}

Jenis-jenis bank berdasarkan Undang-Undang Nomor 10 Tahun 1998 yaitu bank umum dan bank perkreditan rakyat (BPR ). Jenis-jenis bank berdasarkan fungsinya menurut (Taswan, 2010) yaitu bank komersial, bank pembangunan, dan bank tabungan. Jenis-jenis bank berdasarkan kepemilikannya menurut Kasmir (2012:29-31) yaitu bank milik pemerintah, bank milik swasta nasional, bank milik asing, dan bank milik campuran. Jenis bank berdasarkan kegiatan devisa menurut (Taswan, 2010) yaitu bank devisa dan bank non devisa.

\section{Variabel Penelitian}

Dalam penelitian ini input yang digunakan adalah simpanan, biaya tenaga kerja, jumlah karyawan, jumlah ATM dan total aset, sedangkan variabel outputnya adalah pendapatan operasional, kredit yang diberikan, dan return on asset (ROA)

\section{Teori Efisiensi}

Prinsip manajemen perusahaan menuntut baik dalam menggunakan atau memperoleh dana harus pada pertimbangan efisiensi dan efektivitas, artinya setiap dana yang tertanam dalam aktiva harus dapat digunakan seefisien mungkin untuk dapat menghasilkan keuntungan investasi yang maksimal (Riyanto, 2008 :4).

\section{Data Envelopment Analysis (DEA)}


DEA adalah pengembangan program linier yang didasarkan pada teknik pengukuran kinerja relatif dari sekelompok unit input dan output. DEA dapat mengatasi keterbatasan yang dimiliki analisis rasio parsial maupun regresi berganda. DEA merupakan prosedur yang dirancang secara khusus untuk mengukur efisiensi relatif suatu Decision Making Unit (DMU)yang menggunakan banyak input dan output (Sulistyono, 2014).

Menurut Nugraha (2013) Data Envelopment Analysis (DEA) diperkenalkan oleh Charnes, Cooper dan Rhodes pada tahun 1978. DEA dibuat sebagai alat bantu atau alat analisis untuk mengevaluasi kinerja suatu aktivitas dalam sebuah unit entitas atau organisasi. Pada dasarnya prinsip kerja DEA adalah membandingkan data input dan output dari suatu organisasi data (decision making unit, DMU) dengan data input dan output lainnya pada DMU yang sejenis. Perbandingan ini dilakukan untuk mendapatkan suatu nilai efisiensi.

\section{METODE}

Penelitian ini menggunakan data sekunder, yaitu data yang diperoleh dari dokumen publikasi yang sudah dalam bentuk jadi yakni laporan keuangan publikasi bank umum yang diterbitkan oleh Otoritas Jasa Keuangan. Teknik pengumpulan data yang digunakan dalam penelitian ini adalah teknik dokumentasi.

Pada penelitian ini objek penelitiannya adalah bank umum konvensional, yaitu dengan jumlah 115 bank sebagai populasinya. Menurut Sugiyono (2006 : 90) sesuai dengan teknik pemilihan data purposive sampling yang diambil kriteria- kriteria yang ditentukan serta dengan pertimbangan tertentu, maka ditentukan sampel objek bank yang akan dimasukkan dalam analisis efisiensi dengan metode DEA sebanyak 8 bank dari keseluruhan populasi bank. Bankbank tersebut adalah 4 bank pemerintah yaitu Bank Mandiri, Bank BNI, Bank BRI, dan Bank BTN dan 4 bank umum swasta nasional devisa yaitu Bank BCA, Bank Danamon, Bank CIMB, dan Bank PANIN.

Menurut Hadad et al. (2003), terdapat tiga pendekatan yang lazim digunakan dalam metode parametrik dan non-parametrik untuk mendefinisikan hubungan input dan output dalam kegiatan finansial suatu lembaga keuangan, yaitu:

1. Pendekatan Aset (Asset Approach)

2. Pendekatan Produksi (Production Approach)

3. Pendekatan Intermediasi (Intermediation Approach)

Penelitian tingkat efisiensi perbankan yang dilakukan dalam penelitian ini didasarkan pada beberapa variabel yang mengacu pada fungsi bank sebagai lembaga intermediasi dan penelitian terdahulu, yang digolongkan menjadi 2 variabel yaitu variabel input dan variabel 
output. Variabel inputnya terdiri dari simpanan, biaya tenaga kerja, jumlah karyawan, jumlah ATM dan total aset. Variabel output dalam penelitian ini adalah kredit yang disalurkan, pendapatan operasional, dan ROA.

Dalam mengukur efisiensi dengan DEA langkah penting yang dilakukan adalah penentuan variabel-variabel input dan variabel-variabel output. Selanjutnya menentukan orientasi model, apakah bertujuan untuk memaksimalkan output atau meminimalkan input. Hubungan antara input dengan output, apakah bersifat variable return to scale atau constant return to scale juga merupakan aspek yang penting dalam teknik DEA. Dalam hal hubungan antara input dengan output bersifat constant return to scale, efisiensi teknis yang hendak dicapai tidak mencerminkan skala ekonomi yang efisien. Sedangkan dalam hubungan input dan output yang variabel return to scale menganggap efisiensi yang dicapai juga menggambarkan efisiensi dalam skala ekonomi. Artinya bank yang tidak efisien dalam teknis juga tidak efisien dalam skala ekonomi, bank yang efisien dalam teknis juga efisien dalam skala ekonomi (Kurnia, 2004). Dalam penelitian ini penentuan hubungan variabel bersifat constant return to scale.

\section{HASIL DAN PEMBAHASAN}

\section{Perbandingan Tingkat Efisiensi Deangan DEA}

Berdasarkan hasil pengolahan data yang telah dilakukan dengan metode Data Envelopment Analysis (DEA) dengan menggunakan software Banxcia Frontier Analysis (BFA). Analisis penulis terkait hasil pengolahan adalah sebagai berikut

Tabel 1 Nilai Efisiensi Bank Konvensional Di Indonesia Tahun 2014-2018

\begin{tabular}{|l|c|c|c|c|c|}
\hline \multirow{2}{*}{\multicolumn{1}{|c|}{ Nama Bank }} & \multicolumn{5}{|c|}{ Tahun } \\
\cline { 2 - 6 } & $\mathbf{2 0 1 4}$ & $\mathbf{2 0 1 5}$ & $\mathbf{2 0 1 6}$ & $\mathbf{2 0 1 7}$ & $\mathbf{2 0 1 8}$ \\
\hline Bank Mandiri & $100 \%$ & $100 \%$ & $100 \%$ & $95,16 \%$ & $98,59 \%$ \\
\hline Bank BNI & $100 \%$ & $88,20 \%$ & $94,44 \%$ & $93,59 \%$ & $94,73 \%$ \\
\hline Bank BRI & $100 \%$ & $100 \%$ & $100 \%$ & $100 \%$ & $100 \%$ \\
\hline Bank BTN & $100 \%$ & $100 \%$ & $100 \%$ & $100 \%$ & $100 \%$ \\
\hline Bank BCA & $100 \%$ & $100 \%$ & $100 \%$ & $100 \%$ & $100 \%$ \\
\hline Bank Danamon & $100 \%$ & $100 \%$ & $100 \%$ & $100 \%$ & $100 \%$ \\
\hline Bank CIMB & $100 \%$ & $100 \%$ & $100 \%$ & $100 \%$ & $100 \%$ \\
\hline Bank Panin & $100 \%$ & $100 \%$ & $100 \%$ & $100 \%$ & $100 \%$ \\
\hline
\end{tabular}

\section{Sumber : Data yang diolah dengan Banxia Frontier Analysis (BFA), 2019}

Dari Tabel 1 diketahui bahwa pada dasarnya kinerja Bank Mandiri, Bank BNI, Bank BTN, Bank BCA, Bank Danamon, Bank CIMB dan Bank PAN sudah efisien karena delapan bank tersebut sudah mampu mencapai skor $100 \%$ yang berarti bank-bank tersebut sudah 
mampu mengoptimalkan input dan memaksimalkan output, akan tetapi ada beberapa tahun dari masing-masing bank yang masih kurang efisien karena belum mencapai skor 100\%. Bank BNI memiliki tingkat efisiensi yang paling rendah diantara delapan bank tersebut karena dari 5 (lima) tahun periode penelitian bank tersebut hanya satu tahun mencapai tingkat yang efisien pada tahun 2014 dan selama empat tahun kinerjanya tidak efisien, yang berarti pemanfaatan input yang belum optimal untuk menghasilkan output, sedangkan untuk Bank Mandiri memiliki tingkat efisiensi lebih baik karena dari 5 (lima) tahun periode penelitian bank tersebut mengalami 2 (dua) tahun kinerjanya tidak efisien. Dalam golongan bank BUMN bank yang mengalami efisiensi selama periode penelitian yaitu Bank BTN dan Bank BRI. Sedangkan untuk golongan bank swasta devisa yaitu Bank BCA, Bank Danamon, Bank CIMB dan Bank PAN mengalami efisiensi selama periode penelitian.

\section{Pembahasan}

Berdasarkan hasil penelitian ini menunjukkan bahwa tidak semua bank yang menjadi sampel mencapai tingkat efisiensi pada penelitian periode tahun 2014-2018. Dengan menggunakan metode DEA, dan variabel yang ditentukan, terdapat 2 bank yang tidak mencapai tingkat efisiensi. Bank-bank tersebut adalah bank pemerintah.

Bank-bank yang kurang mencapai tingkat efisiensi adalah Bank Mandiri dan Bank BNI atau 2 (dua) bank dari sampel bank pemerintah. Sedangkan untuk kelompok bank swasta nasional devisa telah mencapai tingkat efisiensi $100 \%$ atau secara keseluruhan dari 4 (empat) sampel yang ada. Dilihat dari jumlah bank yang kurang efisien dari masing-masing kelompok bank, menunjukkan bahwa bank swasta nasional devisa lebih banyak mencapai tingkat efisiensi dibandingkan dengan bank pemerintah.

Analisis mengenai jumlah variabel-variabel yang dinaikkan dan diturunkan untuk mencapai tingkat efisiensi dari masing-masing bank yang tidak mencapai tingkat efisiensi pada tahun 2018 adalah sebagai berikut:

Tabel 2 Skenario Perbaikan Efisiensi Intermediasi PT Bank Mandiri (Persero), Tbk.

\begin{tabular}{|l|rr|rr|r|}
\hline \multicolumn{1}{|c|}{ Variabel } & \multicolumn{2}{c|}{ Actual } & \multicolumn{2}{c|}{ Target } & Potential Improvment \\
\hline Biaya Tenaga Kerja & $\mathrm{Rp}$ & 11.798 .611 & $\mathrm{Rp}$ & $8.479 .853,23$ & $-28,13$ \\
\hline Jumlah ATM & & 17376 & & 7507,47 & $-56,79$ \\
\hline Jumlah Karyawan & & 39.809 & 39.809 & 0,00 \\
\hline Simpanan & $\mathrm{Rp}$ & 739.486 .534 & $\mathrm{Rp}$ & $717.530 .304,84$ & $-2,97$ \\
\hline Total Aset & $\mathrm{Rp}$ & 1.037 .077 .806 & $\mathrm{Rp} 1.037 .077 .806,00$ & 0,00 \\
\hline Kredit & $\mathrm{Rp}$ & 718.966 .846 & $\mathrm{Rp}$ & $729.248 .050,90$ & 1,43 \\
\hline Pendapatan Oprasional & $\mathrm{Rp}$ & 66.736 .217 & $\mathrm{Rp}$ & $84.565 .824,90$ & 26,72 \\
\hline ROA & & 3,17 & & 4,55 & 43,44 \\
\hline
\end{tabular}

Sumber : Data yang diolah dengan Banxia Frontier Analysis (BFA), 2019 
Dilihat dari Tabel 2 jumlah input lebih besar dari target untuk mendapatkan nilai efisiensi, sehingga untuk mencapai tingkat efisiensi dapat menurunkan biaya tenaga kerja, jumlah ATM, dan jumlah simpanan atau dengan menaikkan jumlah output kredit, pendapatan operasional dan ROA. Input jumlah karyawan dan total aset tidak mengalami perubahan karena penerimaannya sudah mencapai target $100 \%$.

Menurut Kasmir (2012:184), pemberhentian karyawan dapat dilakukan karena karyawan lalai dalam menjalankan tugas atau berbuat kecurangan, sehingga menurunkan biaya tenaga kerja. Alternatif lainnya adalah dengan melakukan pelatihan bagi karyawan agar kinerjanya lebih produktif sehingga biaya tenaga kerja dapat efisien. Hal ini sesuai dengan Kasmir (2012:157) yang menyatakan kualitas sumber daya manusia yang ada dalam bank, terutama bagi karyawan yang lama perlu diberikan pelatihan dan pengembangan diri, baik di dalam maupun di luar perusahaan.

Untuk mencapai efisiensi jumlah ATM dapat dilakukan dengan pengurangan mesin ATM yang kurang produktif atau sepi dimana hal ini dapat dilihat dari rata-rata pemanfaatan mesin oleh nasabah dibanding dengan biaya perawatan yang dikeluarkan seperti listrik, $A C$, mesin ATM itu sendiri dan kebersihan, pengurangan mesin ATM ini dapat diimbangi dengan pengoptimalan transaksi digital banking seperi internet banking, mobile banking, dan SMS banking, dan juga letak mesin ATM yang kurang strategis juga dapat dipindahkan. Alternatif lainnya yaitu dengan meningkatkan produktivitas mesin ATM dengan memberikan kebijakan minimum transaksi teller, sehingga dimungkinkan transaksi di teller dapat berkurang yang berimbas pula bagi penurunan jumlah karyawan karena digantikan dengan teknologi yang sudah ada. Pada bank Mandiri minimum transaksi yang dapat dilakukan yaitu untuk kartu Mandiri Silver limit transaksi per hari penarikan tunai sebesar Rp 10.000.000, transfer sesama bank mandiri maksimal Rp 25.000.000 dan transfer ke bank lain maksimal Rp 5.000.000, untuk kartu Mandiri Gold limit transaksi per hari penarikan tunai sebesar Rp 10.000.000, transfer sesama bank mandiri maksimal Rp 50.000.000 dan transfer ke bank lain maksimal Rp 10.000.000, untuk kartu Mandiri Platinum limit transaksi per hari penarikan tunai sebesar Rp 10.000.000, transfer sesama bank mandiri maksimal Rp 100.000.000 dan transfer ke bank lain maksimal Rp 25.000.000, dan untuk kartu Mandiri Platinum Plus limit transaksi per hari penarikan tunai sebesar Rp 10.000.000, transfer sesama bank mandiri tak terbatas dan transfer ke bank lain maksimal Rp 25.000.000. Selain dari sisi tarik tunai dan transfer dalam hal setor tunai di ATM bank mandiri juga tidak memiliki limit transaksi, sehingga bagi yang ingin melakukan transaksi penarikan tunai dan transfer di bawah batas maksimum masing-masing 
kartu serta setor tunai dapat melakukannya di ATM. Hal ini secara tidak langsung juga mendorong adanya pengurangan biaya tenaga kerja.

Dalam hal penurunan simpanan dapat dilakukan dengan cara mengurangi promosi simpanan, sehingga menurunkan minat nasabah untuk menyimpan dananya dalam bentuk simpanan, alternatif lainya dapat disimpan dalam investasi lainnya seperti surat berharga. Bank Mandiri sendiri menjadi agen penjual surat berharga berupa obligasi negara ritel (ORI) dan reksa dana.

Dari sisi output dalam meningkatkan efisiensi dapat dilakukan dengan menaikkan kredit yang disalurkan hal ini dapat dilakukan dengan cara menurunkan suku bunga kredit agar lebih kompetitif dan gencar dalam melalukan promosi, sehingga minat masyarakat menggunakan kredit dapat meningkat, namun tetap berdasarkan prinsip kehati-hatian. Dari sisi output selain kredit, dalam meningkatkan efisiensi dapat dilakukan dengan menaikkan pendapatan operasional hal ini dapat dilakukan dengan mencari nasabah yang banyak khususnya nasabah kredit. Bank bisa menekan biaya bunga agar lebih kompetitif dan gencar dalam melalukan promosi terkait kredit. Selain itu bank juga dapat meningkatkan pendapatannya dengan memperbanyak transaksi jasa sehingga menaikkan pendapatan provisi dan komisi, menurut (Kasmir 2012:128) bahwa disamping keuntungan utama dari kegiatan pokok perbankan, yaitu dari selisih bunga simpanan dan bunga pinjaman (Spread Based) maka pihak perbankan juga dapat memperoleh keuntungan lainnya, yaitu transaksi yang diberikan dalam jasa-jasa bank yang disebut fee based. Layanan jasa yang dimiliki oleh bank mandiri sendiri beragam seperti pengiriman uang, collection, safe deposit box, dan layanan tanpa kantor. Bank mandiri juga merupakan bank devisa sehingga bisa mendapatkan pendapatan dari transaksi valas. Peningkatan pendapatan operasional ini sejalan dengan peningkatan ROA dalam mencapaian efisiensi.

Output ROA dapat ditingkatkan untuk mencapai efisiensi dengan cara meningkatkan pendapatan sesuai dengan alternatif diatas dan menurunkan total aset untuk mencapai efisiensi dapat dilakukan dengan cara mengurangi jumlah aset-aset non produktif seperti properti yang terbengkalai, aset yang diambil alih, rekening tunda, aset antar kantor dan aset non produktif lainnya. 
Tabel 3 Skenario Perbaikan Efisiensi Intermediasi PT Bank Negara Indonesia (Persero), Tbk.

\begin{tabular}{|l|rr|rr|r|}
\hline \multicolumn{1}{|c|}{ Variabel } & \multicolumn{2}{c|}{ Actual } & \multicolumn{2}{c|}{ Target } & Potential Improvment \\
\hline Biaya Tenaga Kerja & $\mathrm{Rp}$ & 8.106 .388 & $\mathrm{Rp}$ & $8.106 .388,00$ & 0,00 \\
\hline Jumlah ATM & & $18.311,00$ & & $10.344,87$ & $-43,50$ \\
\hline Jumlah Karyawan & & $27.224,00$ & & $27.224,00$ & 0,00 \\
\hline Simpanan & $\mathrm{Rp}$ & 544.659 .543 & $\mathrm{Rp}$ & $544.659 .543,00$ & 0,00 \\
\hline Total Aset & $\mathrm{Rp}$ & 754.575 .210 & $\mathrm{Rp}$ & $747.792 .101,52$ & $-0,90$ \\
\hline Kredit & $\mathrm{Rp}$ & 483.421 .821 & $\mathrm{Rp}$ & $511.680 .852,95$ & 5,85 \\
\hline Pendapatan Oprasional & $\mathrm{Rp}$ & 61.901 .978 & $\mathrm{Rp}$ & $65.344 .172,19$ & 5,85 \\
\hline ROA & & 2,78 & & 3,35 & 20,65 \\
\hline
\end{tabular}

\section{Sumber : Data yang diolah dengan Banxia Frontier Analysis (BFA), 2019}

Dilihat dari Tabel 3 jumlah input lebih besar dari target untuk mendapatkan nilai efisiensi, sehingga untuk mencapai tingkat efisiensi dapat menurunkan jumlah ATM, dan total aset atau dengan menaikan jumlah output kredit, pendapatan operasional dan ROA. Input biaya tenaga kerja, jumlah karyawan, dan simpanan tidak mengalami perubahan karena penerimaannya sudah mencapai target $100 \%$.

Untuk mencapai efisiensi jumlah ATM dapat dilakukan dengan pengurangan mesin ATM yang kurang produktif atau sepi dimana hal ini dapat dilihat dari rata-rata pemanfaatan mesin oleh nasabah dibanding dengan biaya perawatan yang dikeluarkan seperti listrik, $A C$, mesin ATM itu sendiri dan kebersihan, pengurangan mesin ATM ini dapat diimbangi dengan pengoptimalan transaksi digital banking seperti internet banking, mobile banking, dan SMS banking, dan juga letak mesin ATM yang kurang strategis juga dapat dipindahkan atau diubah menjadi ATM Drive Thru dan ATM Ride Thru. Alternatif lainnya yaitu dengan meningkatkan produktivitas mesin ATM dengan memberikan kebijakan minimum transaksi teller, sehingga dimungkinkan transaksi di teller dapat berkurang yang berimbas pula bagi penurunan jumlah karyawan karena digantikan dengan teknologi yang sudah ada. Pada bank BNI maksimal transaksi per hari dari ATM dengan kartu BNI Siver penarikan tunai sebesar Rp 5.000.000, transfer sesama bank BNI Rp 50.000.000 dan transfer bank lain Rp 10.000.000, untuk kartu BNI Gold tarik tunai sebesar Rp 10.000.000, transfer sesama bank BNI Rp 100.000.000 dan transfer bank lain Rp 15.000.000, dan untuk BNI Platinum tarik tunai sebesar Rp 10.000.000, transfer sesama bank BNI Rp 100.000.000 dan transfer bank lain Rp 25.000.000. Selain dari sisi tarik tunai dan transfer dalam hal setor tunai di ATM bank BNI juga tidak memiliki limit transaksi, sehingga bagi yang ingin melakukan transaksi penarikan tunai dan transfer di bawah batas maksimum masing-masing kartu serta setor tunai dapat melakukannya di ATM.

Menyiasati penurunan total aset untuk mencapai efisiensi dapat dilakukan dengan cara mengurangi jumlah aset-aset non produktif seperti properti yang terbengkalai, aset yang 
diambil alih, rekening tunda, aset antar kantor dan aset non produktif lainnya. Penurunan total aset ini sejalan dengan peningkatan ROA dalam mencapai efisiensi.

Dari sisi output dalam meningkatkan efisiensi dapat dilakukan dengan menaikkan kredit yang disalurkan hal ini dapat dilakukan dengan cara menurunkan suku bunga kredit agar lebih kompetitif dan gencar dalam melalukan promosi, sehingga minat masyarakat menggunakan kredit dapat meningkat, namun tetap berdasarkan prinsip kehati-hatian.

Untuk meningkatkan pendapatan operasional dapat dilakukan dengan mencari nasabah yang banyak khususnya nasabah kredit. Bank bisa menekan biaya bunga agar lebih kompetitif dan gencar dalam melalukan promosi terkait kredit. Selain itu bank juga dapat meningkatkan pendapatannya dengan memperbanyak transaksi jasa sehingga menaikkan pendapatan provisi dan komisi, menurut (Kasmir 2012:128) bahwa disamping keuntungan utama dari kegiatan pokok perbankan, yaitu dari selisih bunga simpanan dan bunga pinjaman (Spread Based) maka pihak perbankan juga dapat memperoleh keuntungan lainnya, yaitu transaksi yang diberikan dalam jasa-jasa bank yang disebut fee based. Layanan jasa yang dimiliki oleh bank BNI sendiri beragam seperti BNI Transfer, Kirim Uang Internasional, BNI Safe Deposit Box, BNI Multiguna Voucher, BNI Inkaso, BNI Surat Keterangan Bank, BNI Trevellers Cheque, dan Uang kertas asing. Bank mandiri juga merupakan bank devisa sehingga bisa mendapatkan pendapatan dari transaksi valas.

Output ROA dapat ditingkatkan untuk mencapai efisiensi dengan cara peningkatan pendapatan operasional dan menurunkan total aset yang dapat dilakukan dengan alternatif yang telah disebutkan diatas.

\section{PENUTUP}

\section{Kesimpulan}

Penelitian ini dilakukan dengan tujuan menganalisis efisiensi perbankan menggunakan metode non parametrik Data Envelopment Analysis (DEA) pada bank umum konvensional di Indonesia pada tahun 2014-2018. Beradsarkan data yang diperoleh penulis terdapat populasi sebanyak 115 bank, dengan teknik purposive sampling dan dengan kriteria-kriteria yang telah ditetapkan hanya 8 bank yang masuk ke dalam sampel penelitian dan dianalisis dengan metode non parametrik DEA.

PT Bank Mandiri (Persero), Tbk., mengalami pencapaian efisiensi 100\% pada tahun 2014 sampai dengan 2016, namun pada tahun 2017 hanya mencapai efisiensi 95,16\% dan pada tahun 2018 mampu menaikkan efisiensinya menjadi 98,59\%. PT Bank Negara Indonesia (Persero), Tbk., mengalami pencapaian efisiensi 100\% pada tahun 2014, namun pada tahun- 
tahun berikutnya yaitu tahun 2015, 2016, 2017 dan 2018, PT Bank Negara Indonesia (Persero), Tbk., mencapai efisiensi 88,20\%, 94,44\%, 93,59\%, dan 94,73\%. PT Bank Rakyat Indonesia (Persero), Tbk., dan PT Bank Tabungan Negara (Persero), Tbk., merupakan bank milik pemerintah yang mengalami efisiensi $100 \%$ selama periode penelitian. Bank umum swasta nasional devisa yang masuk dalam objek penelitian ini yaitu PT Bank Central Asia, Tbk., PT Bank Danamon Indonesia, Tbk., PT Bank CIMB Niaga, Tbk., dan PT PAN Indonesia Bank, Tbk., mengalami efisiensi 100\% selama periode penelitian.

Terdapat perbedaan kinerja antara bank milik pemerintah dan bank swasta nasional devisa dari tingkat efisiensinya, bank swasta nasional devisa lebih unggul dibandingkan dengan bank pemerintah, hal ini sejalan dengan penelitian Nugraha (2013). Selain itu, dilihat dari variabel input dan outputnya bank swasta nasional devisa lebih sedikit dalam menjalankan fungsi intermediasinya dibandingkan dengan bank milik pemerintah.

Berdasarkan perhitungan yang dihasilkan oleh Data Envelopment Analysis (DEA) bank yang mengalami inefisien tahun 2018 adalah PT Bank Mandiri (Persero), Tbk. dan PT Bank Negara Indonesia (Persero), Tbk.

Analisis mengenai jumlah variabel yang dinaikkan dan diturunkan untuk mencapai efisiensi berdasarkan skenario yang dihasilkan, maka PT Bank Mandiri (Persero), Tbk., dapat menurunkan biaya tenaga kerja, jumlah ATM, dan jumlah simpanan atau dengan menaikkan jumlah output kredit, pendapatan operasional dan Return On Asset (ROA). PT Bank Negara Indonesia (Persero), Tbk., dapat menurunkan jumlah ATM dan total aset atau dengan menaikkan jumlah output kredit, pendapatan operasional dan Return On Asset (ROA) sehingga mencapai efisiensi.

\section{Keterbatasan}

Hambatan dalam penelitian ini diantaranya metode Data Envelopment Analysis (DEA) hanya dapat mengukur efisiensi relatif (karena hanya membandingkan dengan bank-bank dalam sampel) sehingga sangat memungkinkan tidak mencerminkan efisiensi yang sebenarnya dari bank-bank yang diteliti, aplikasi yang digunakan tidak dapat merangking efisiensi yang terbaik dari bank-bank yang telah mencapai tingkat efisiensi $100 \%$, pendekatan penelitian ini hanya menitikberatkan pada pendekatan intermediasi, penelitian ini hanya menggunakan biaya tenaga kerja dan tidak mempertimbangkan biaya lainnya.

\section{Agenda Penelitian Mendatang}

Penulis menyarankan bank sebaiknya memanfaatkan analisis DEA guna mengukur efisiensi kinerja keuangan karena dengan begitu bank bisa mengoptimalkan input untuk menghasilkan output yang maksimal sehingga bank dapat menjalankan fungsi intermediasi dan 
meningkatkan profitabilitas, untuk penelitian selanjutnya dapat menggunakan metode Data Envelopment Analysis (DEA) dengan lebih banyak objek dan variabel sehingga mencerminkan efisiensi yang sebenarnya.

Penulis menyarankan usaha perbaikan efisiensi dapat dilakukan oleh bank-bank yang belum efisien dengan belajar dari bank swasta nasional devisa yang menduduki peringkat teratas selama periode penelitian yakni 2014-2018, mempertimbangkan skenario perbaikan atas efisiensi, melakukan praktik-praktik perbankan yang baik serta dibarengi dengan pengembangan sumber daya manusia dan penerapan teknologi yang lebih maju.

Penulis menyarankan penelitian ini menggunakan pengukuran efisiensi dengan metode DEA dengan spesifikasi input output berdasarkan pendekatan intermediasi namun penelitian ini juga dapat dikembangkan lagi dengan pendekatan lain, diantaranya pendekatan aset, pendekatan pendapatan atau pendekatan produksi.

Secara teknis penghitungan dalam penelitian ini dibantu dengan Banxcia Frontier Analysis (BFA), namun penelitian selanjutnya dapat menggunakan aplikasi lain yang semakin berkembang untuk kebutuhan penelitian.

\section{DAFTAR PUSTAKA}

Abidin, Zaenal dan Endri. 2009. Kinerja Efisiensi Teknis Bank Pembangunan Daerah: Pendekatan Data Envelopment Analysis (DEA). Jurnal Akuntansi Dan Keuangan, Vol. 11, No. 1, Mei 2009: 21-29.

Abidin, Zaenal. 2007. Kinerja Efisiensi Pada Bank Umum. Jurnal Ekonomi Vol 2.

Dendawijaya, Lukman. 2010. Manajemen Perbankan. Jakarta: Galia Indonesia.

Hadad, Muliaman D., et al. 2003. Analisis Efisiensi Industri Perbankan Indonesia: Penggunaan Metode Nonparametrik Data Envelopment Analysis (DEA). Biro Stabilitas Sistem Keuangan Bank Indonesia. Research Paper, No. 7/5.

Infobank. 2018. Analisis - Strategi Perbankan dan Keuangan. Juli 2018.

Indrianto, N dan B. Supomo. 1999. Metodologi Penelitian Bisnis. Yogyakarta: BPFE.

Kasmir. 2010. Bank dan Lembaga Keuangan Lainnya. Jakarta: PT. Raja Grafindo Persada. Kasmir. 2012. Manajemen Perbankan. Jakarta : PT. Raja Grafindo Persada.

Kamus Bisnis dan Bank. http://www.mediabpr.com/kamus-bisnisbank/biaya_tenaga_kerja.aspx.

Kusmargiani, Ida S. 2006. Analisis Efisiensi Operasional Dan Efisiensi Profitabilitas Pada Bank Yang Marger Dan Akuisis Di Indonesia. Pasca Sarjana Megister Manajemen Undip. 
Kurnia, A. S. 2004. Mengukur Efisiensi Intermediasi Sebelas Bank Terbesar Indonesia Dengan Pendekatan Data Envelopment Analysis (DEA). Jurnal Bisnis Strategi. 13: 127-139.

Nugraha, Bhava Wahyu. 2013. Analisis Efisiensi Perbankan Menggunakan Metode Non Parametrik Data Envelopment Analysis (DEA). Jurnal Manajemen. Vol 1 No 1.

PSAK No. 16 revisi tahun 2011.

PSAK No 23 Paragraf 6 IAI (2010:23.3).

Soewadji, Jusuf. 2012. Pengantar Metodologi Penelitian. Jakarta : Mitra Wacana Media.

Statistik Perbankan Indonesia Otoritas Jasa Keuangan.

Sulistyono, Bayu. 2014. Pengukuran Efisiensi Bank BUMN Di Indonesia Dengan Menggunakan Metode Data Envelopment Analysis. Jurnal Megister Manajemen.

Sugiyono. 2006. Metode Penelitian Kuantitatif, Kualitatif dan $R \&$ D. Bandung: Alfabeta.

Taswan. 2010. Manajemen Perbankan, Konsep, Teknik, dan Aplikasi. Edisi Kedua. Yogyakarta : UPP STIM YKPN.

Undang-Undang Negara Republik Indonesia Nomor 10 Tahun 1998. 